\title{
A Combined Optical-Microwave Method to Retrieve Soil Moisture over Vegetated Areas
}

\author{
Cristian Mattar, Jean-Pierre Wigneron, José A. Sobrino, Nathalie Novello, Jean Christophe Calvet, \\ Clément Albergel, Philippe Richaume, Arnaud Mialon, Dominique Guyon, Juan C. Jiménez-Muñoz
}

\begin{abstract}
A simple approach for correcting the effect of vegetation in the estimation of the surface soil moisture $\left(w_{S}\right)$ from L-band passive microwave observations is presented in this study. The approach is based on semi-empirical relationships between soil moisture and the polarized reflectance including the effect of the vegetation optical depth which is parameterized here as a function of the Normalized Vegetation Difference Index (NDVI). In a first step, the method was tested against in-situ measurements collected over a grass site from years 2004 to 2007 (SMOSREX experiment) Two polarizations (horizontal/vertical) and five incidence angles $\left(20^{\circ}, 30^{\circ}, 40^{\circ}, 50^{\circ}\right.$ and $\left.60^{\circ}\right)$ were considered in the analysis. The best $w_{\mathrm{S}}$ estimations were obtained when using both polarizations at the angle of $40^{\circ}$. The average accuracy in the soil moisture retrievals was found to be about $0.06 \mathrm{~m} 3 / \mathrm{m} 3$, improving the estimations by about $0.02 \mathrm{~m} 3 / \mathrm{m3}$ in comparison with the case when the vegetation effect is not considered. In a second step, the proposed method was applied to the microwave observations acquired from the Soil Moisture Ocean Satellite (SMOS) and optical observations acquired from the Moderate Resolution Imaging Spectroradiometer (MODIS) over Australia for $\mathbf{2 0 1 0}$ in order to evaluate its applicability to spaceborne remote sensing observations. The results showed the potential interest of using information on vegetation (through a vegetation index such as NDVI), in the semi-empirical regressions which were calibrated over the Australian site.
\end{abstract}

Index Terms-Soil moisture, L-band, NDVI, surface temperature.

\section{INTRODUCTION}

$\mathrm{S}$ oil moisture (SM) plays a key role in the hydrological cycle and land-atmosphere interactions. Several studies documented the importance of soil moisture in a wide range of scientific areas, for instance,climate simulations and weather forecast [1-6], crop growth simulation models [7-8], rainfallrunoff transformation models [9], soil evaporation and plant transpiration [10-12], among others.

Manuscript will submitted on May, 2011.

C. Mattar , J. A. Sobrino, and J.C. Jiménez-Muñoz are with the Global Change Unit (GCU), Image Processing Laboratory, University of Valencia, c/ Catedrático Agustín Escardino $N^{\circ} 9$ - 46980 Paterna, Valencia, Spain (email: cristian.mattar@uv.es).

J.-P. Wignerorn, N. Novello, and D. Guyon are with Ecologie Fonctionnelle et Physique de l'Environnement (EPHYSE), Institut National de la Recherche Agronomique (INRA), 33883 Villenave d'Ornon Cedex, France.

J.-C. Calvet is with the Météo-France Centre National de Recherches Meteorologiques, 31057 Toulouse, France.

C. Albergel is with the European Centre for Medium-Range Weather Forecasts (ECMWF), Shinfield Park, Reading, RG2 9AX, United Kingdom.

P. Richaume, A. Mialon and Y. Kerr are with the the Centre d'Etudes Spatiales de la Biosphère (CESBIO), 31401 Toulouse Cedex 09, France.
Despite the multidisciplinary importance of surface soil moisture, reliable regional and regular determination of this variable is very difficult through conventional point measurements [13]. Thus, remote sensing techniques appear as a potential tool to assess soil moisture at different scales. In this context, previous research has shown that passive microwave measurements are the most relevant remote sensing technique to monitor soil moisture over land surface at global scale [14-18]. In particular, microwave observations at L-band frequencies $(1.4 \mathrm{GHz})$, are very interesting as they have a high sensitivity to soil moisture and a low sensitivity to the cloud cover and to the atmospheric effects.

Recently, the Soil Moisture and Ocean Salinity (SMOS) mission has been launched. The baseline SMOS payload is an L-band (1.4 GHz) two dimensional (2D) interferometric radiometer that aims at providing global maps of soil moisture with an accuracy better than $4 \%$ (in $\mathrm{m}^{3} / \mathrm{m}^{3}$ ) every 3 days and with a resolution better than $50 \mathrm{~km}$ [19]. In the near future, the Soil Moisture Active Passive (SMAP) mission will be the second spacecraft platform estimating the surface soil moisture at L-band [20]. These L-band passive microwave technologies generate an important challenge in developing efficient soil moisture retrieval algorithms. The main difficulty in the estimation of soil moisture by using L-band radiometry arises from the presence of the overlying vegetation: the vegetation layer attenuates the soil emission and adds its own emission to the land surface emission. Nevertheless, several authors have developed simple approaches to account for the vegetation effects $[16,21]$. These approaches are generally based on the so-called "tau-omega" model, which is based on the optical depth $(\tau)$, accounting for vegetation attenuation effects, and the single-scattering albedo $(\omega)$, accounting for vegetation scattering effects. The L-band Microwave Emission of the Biosphere (L-MEB) model used in the SMOS level-2 algorithms [22-23] is also based on the "tau-omega" model.

As an alternative to the use of retrieval algorithms based on forward model inversion [18], vegetation effects at L-band have been taken into account in several works using semiempirical regressions based on bi-angular [24] or bipolarization observations [25-27]. However, these approaches were based solely on microwave observations and did not attempt to use additional information on the vegetation development, as provided by optical indexes in the optical domain, such as the Normalized Difference Vegetation Index (NDVI) or the Enhanced Vegetation Index (EVI) [28]. 
Therefore, the aim of this paper is to evaluate a simple regression method to estimate the surface soil moisture using combined microwave and optical data accounting for the vegetation effects. The method is based on the semi-empirical regressions derived from [24], but including the vegetation effects through the use of the Normalized Difference Vegetation Index (NDVI). In-situ measurements obtained during the long term SMOSREX experiment [29] were used to evaluate the proposed regression approach. An application of the method to spaceborne remote sensing observations is also presented using data acquired from SMOS and the Moderate Resolution Imaging Spectroradiometer (MODIS) sensors.

This paper is structured as follows: Section 2 presents the material and describes the proposed method. Section 3 presents the calibration and validation strategy. Section 4 shows the results obtained in the calibration and validation study over the SMOREX site and also a simple application to combined SMOS/MODIS observations over eastern Australia. Finally, section 5 provides a brief discussion and the conclusion of this study.

\section{DATA}

\section{A. In situ data: The SMOSREX experimental site}

In-situ measurements of soil moisture, surface temperature, radiometric passive microwave temperature and visible/near infrared reflectance acquired in the framework of the Surface Monitoring of the Soil Reservoir Experiment (SMOSREX) field campaign [29] were used in this study. SMOSREX is a part of the Interdisciplinary Field Experiment on Radiometry (PIRRENE) program and is located at the National Office of Aerospace Study and Research (ONERA) test site near the town of Mauzac in France $\left(43^{\circ} 23^{\prime} 8.74 " \mathrm{~N} ; 1^{\circ} 17^{\prime} 32.63 " \mathrm{E} ; 188\right.$ m. a. s. 1.). SMOSREX integrates a number of studies in the field of passive microwaves at L-band, from the development of emission models at L-band to the assimilation of L-band data to estimate soil moisture in the root zone. The experiment started in 2001 but is in full operation since January 2003. The current study is based on the data acquired between $1^{\text {st }}$ January 2004 to $31^{\text {st }}$ December 2007. These years are representative of large variety in terms of meteorological conditions. In particular, precipitations ranged from $474 \mathrm{~mm}$ in 2005 to $766 \mathrm{~mm}$ in 2004 (values for 2006 and 2007 are $624 \mathrm{~mm}$ and $589 \mathrm{~mm}$, respectively).

L-band radiometric observations are obtained by the LEWIS radiometer (L-band radiometer for Estimating Water in Soils), with an accuracy of $0.2 \mathrm{~K}$ and a field of view of $13.5^{\circ}$ at $3 \mathrm{~dB}$ [30]. LEWIS is installed at the top of a $13.7 \mathrm{~m}$ vertical structure over a fallow were natural grasses grows. An automatic scanning is made at five incidence angles $(20,30$, 40, 50, and 60 degrees) over two adjacent areas: a fallow and a bare soil field, eight times per day. In routine mode, LEWIS monitors the brightness temperature of the fallow field at an incidence angle of $40^{\circ}$. Only observations made over the fallow area will be considered in this study.

Soil moisture and temperature profiles are automatically measured with a 30-min time step by, respectively, impedance sensors (ML2 Theta-probes1) and thermistor probes installed at several soil depths. In this study, data measured at the first top soil layers $(0-6 \mathrm{~cm}$ for soil moisture and $1 \mathrm{~cm}$ for surface temperature) were used. A detailed description of soil moisture and temperature profiles measurements can be found in [29]. As an illustration of these measurements, the LEWIS brightness temperature, soil temperature and soil moisture data measured during the study period (2004-2007) over the SMOSREX site are presented in Figure 1.
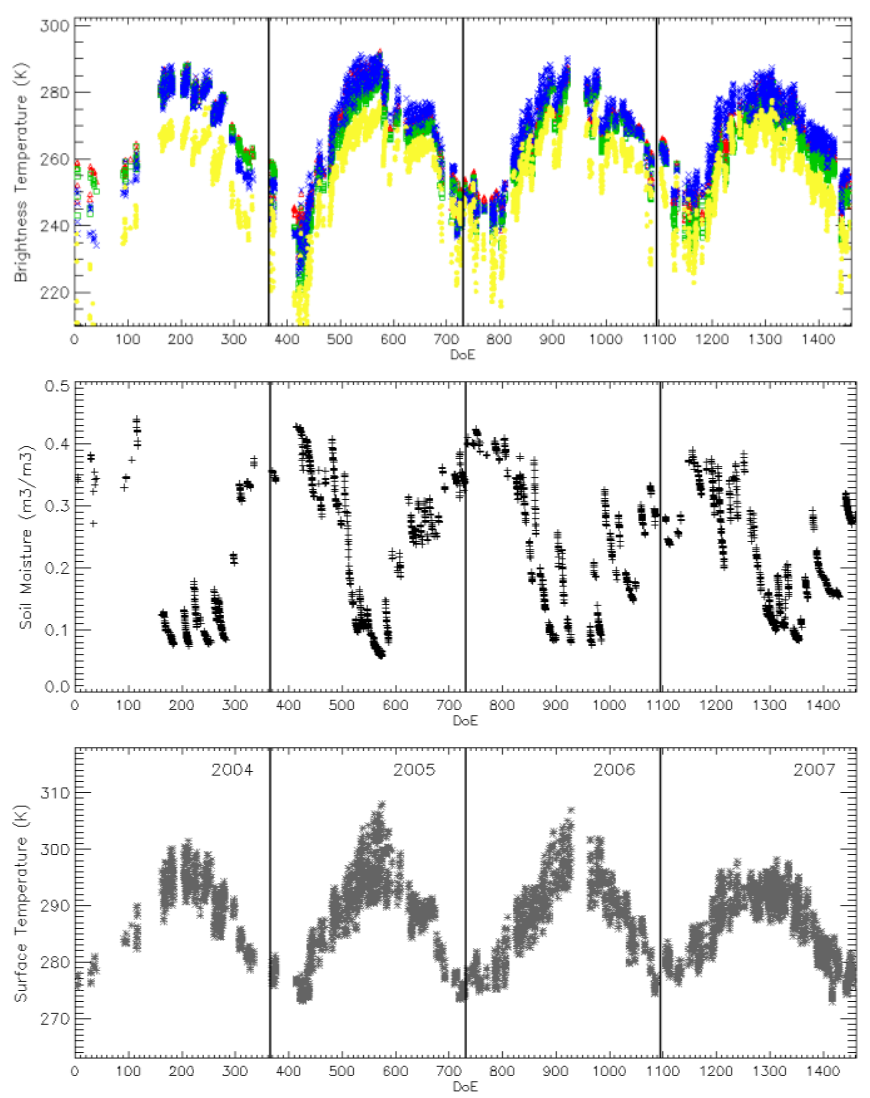

Fig. 1. Time series between 2004 and 2007 measured over the SMOSREX site, (a) brightness temperature at 20 and $40^{\circ}$ vertical and horizontal polarization which are represented by black, red, green and blue respectively, (b) volumetric soil moisture $\left(\mathrm{m}^{3} / \mathrm{m}^{3}\right)$ between $0-5 \mathrm{~cm}$ depth and (c) surface temperature $(\mathrm{K})$ at $0-1 \mathrm{~cm}$ depth.

Vegetation indices (NDVI) were derived from red and nearinfrared reflectance measurements carried out at the incidence angle of $40^{\circ}$ using two CIMEL optical radiometers from July 2003 to December 2007. More details about the reflectance measurements can be obtained in [31]. Figure 2 presents the NDVI values measured over the SMOSREX fallow site. Over the year, two clear vegetation growth periods can be generally seen in spring and at the end of summer. 


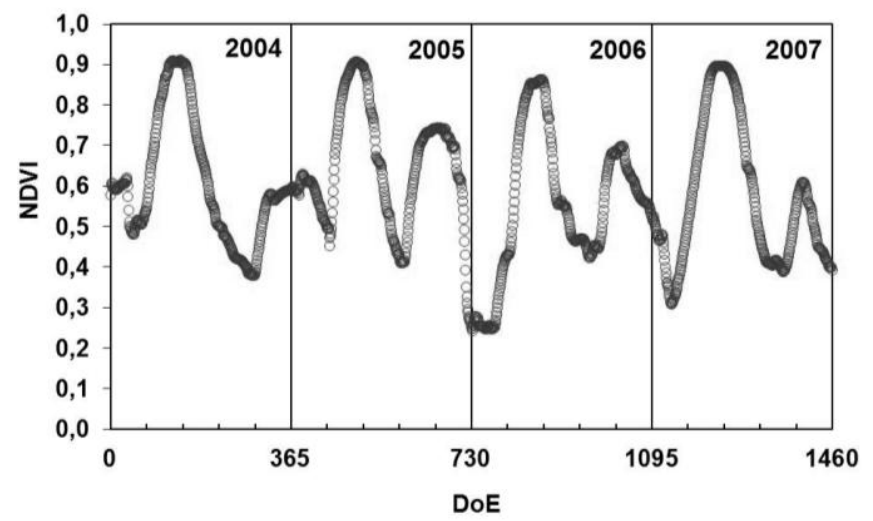

Fig. 2. Daily NDVI values computed from the optical radiometers over the fallow of the SMOSREX site from 2004 to 2007

\section{B. Australian data set}

The proposed algorithm was evaluated over eastern Australia from optical and microwave data acquired, respectively, by MODIS and SMOS in 2010. Passive remote sensing data are provided by the SMOS Level-2 products. These products include the passive microwave brightness temperatures available at both vertical and horizontal polarizations at $42.5^{\circ}$ incidence angle. The temperature values are arranged in a global matrix identified by a single unit of the Discrete Global Grid (DGG). Additionally, the level-2 products contain information on the retrieved soil moisture and optical depth, surface temperature, etc, and quality flags [23]. Optical information from the MODIS sensor was also used. This information concerns the NDVI products available in the MOD13A land product, at a $0.05^{\circ} \times 0.05^{\circ}$ global spatial resolution available and from 16-day composite time series [32]. The studied time period covers September to December 2010.

Global soil moisture data extracted from the ERA-Interim (ERA-int) was also used. The ERA-int was developed by the European Centre for Medium-Range Weather Forecasts (ECMWF) and presents several meteorological and climate information from 1988 to present at $1.5^{\circ} \times 1.5^{\circ}$ latitudelongitude global spatial resolution [33]. The daily averaged volumetric soil moisture in the top soil layer $(\sim 0-7 \mathrm{~cm})$ was used in this study between September to December 2010 over eastern Australia.

\section{ALGORITHM DESCRIPTION}

\section{A. Theoretical basis: the radiative transfer equations}

The development of the regression equations is based on the tau-omega model applied to vegetation covers [14]. The $p$ polarized brightness temperature $\operatorname{Tb}(\theta, p)$ was simply written as a function of the single scattering albedo $\omega(\theta, p)$, the optical depth $\tau(\theta, p)$, the soil reflectivity $\Gamma_{S}(\theta, p)$, and the soil and vegetation effective temperatures $\left(T_{S}^{E}\right.$ and $T_{V}^{E}$, respectively):

$$
\begin{aligned}
T b(\theta, p)= & (1-\omega)(1-\gamma)(1-\gamma \Gamma s) T_{V}^{E}+ \\
& (1-\Gamma s) T_{s}^{E}+T b_{\theta}^{S K Y \downarrow} \Gamma_{S}(\theta, p) \gamma^{2}(\theta, p)
\end{aligned}
$$

where $\gamma=\varkappa(\theta, p)$ is the $p$-polarized transmissivity of the vegetation layer, which can be expressed as a function of the optical thickness $\tau(\theta, p)$, and the incidence angle $\theta$.

$$
\gamma(\theta, p)=\exp \left(-\frac{\tau(\theta, p)}{\cos \theta}\right)
$$

and $T b_{\theta}^{S K Y \downarrow}$ is the downwards atmospheric and galactic brightness temperature. To simplify (1) without introducing significant errors in the result [16], it was assumed that the effective soil and vegetation temperatures were equal ( $T_{S}^{E}=T_{V}^{E}=T_{C}=$ effective surface temperature ).

Additionally, the upwards atmospheric emission can be neglected for ground-based measurements at L-band. The downwards brightness temperature $T B_{\theta}^{S K Y \downarrow}$ is also very small after reflection on the ground and the attenuation through the vegetation [34] and will be neglected in this study.

\section{B. Wigneron's statistical relationships}

Assuming that scattering effects can be neglected, which is generally a good approximation at L-band [35], $\omega$ can be set equal to zero $(\omega=0)$ and the $\tau$ - $\omega$ model can be written as:

$$
T b(\theta, p)=T_{C}\left(1-\Gamma s(\theta, p) \gamma^{2}(\theta, p)\right)
$$

The measured surface emissivity $e(\theta, p)$ defined as $e(\theta, p)=T b(\theta, p) / T c$ can be written as

$$
e(\theta, p)=1-\Gamma_{S}(\theta, p) \gamma^{2}(\theta, p)
$$

Denoting the measured surface reflectivity as $\Gamma(\theta, p)=1-e(\theta, p)$, equation (4) can be rewritten as

$$
\Gamma(\theta, p)=\Gamma_{S}(\theta, p) \gamma^{2}(\theta, p)
$$

Using equation (2) and taking the logarithm function of both terms, equation (5) can be rewritten as

$$
\begin{aligned}
& \cos (\theta) \cdot \log \left(\Gamma_{S}(\theta, p)\right)-2 \tau(\theta, p)= \\
& \cos (\theta) \cdot \log (\Gamma(\theta, p))
\end{aligned}
$$

Since soil reflectivity $\Gamma_{S}(\theta, p)$ is often considered as close to a linear function of surface soil moisture $\left(\mathrm{w}_{\mathrm{S}}\right)$ and it is rather low for very dry soils [15], we assumed that soil reflectivity is proportional to surface soil moisture according to 


$$
\Gamma_{S}(\theta, p) \cong A p(\theta) w_{S}
$$

where $A p(\theta)$ is a coefficient depending on the sensor configuration. The value $A p(\theta)$ is site dependent and implicitly accounts for all the soil characteristics that determine soil emission: mainly soil texture and structure, surface roughness, etc. Many studies in the field of passive microwave remote sensing are based on soil moisture relationships derived from single configuration measurements of the surface emission [36-38]. These latter approaches are appropriate in areas with a low contribution from the vegetation to the surface emission and low roughness effects [25]. It is important to note that the linear approximation in (7) is a crude approximation of the reflectivity curve, which is more typically $S$-shaped and does not go through the origin, especially at $H$ polarization [24].

Using (7), equation (6) can be rewritten as:

$$
\begin{aligned}
\cos (\theta) \cdot \log \left(w_{S}\right)-2 \tau(\theta, p)= & \cos (\theta) \cdot \log (\Gamma(\theta, p))- \\
& \cos (\theta) \cdot \log \left(A_{p}(\theta, p)\right)
\end{aligned}
$$

\section{The new combined approach}

Reordering Equation (8), soil moisture can be expressed as a function of the microwaves reflectivities and the optical depth.

$$
\log \left(w_{S}\right)=a \cdot \log (\Gamma(\theta, p))+b \cdot \tau(\theta, p)+c
$$

where $a, b$ and $c$ are regression coefficients. Optical depth can be generally assumed as independent of incidence angle like $\tau(\theta, p) \cong \tau(p)$ as described in [24]. Additionally, several studies showed that the optical depth can often be related to a vegetation indicator, for instance, the leaf area index (LAI), the Normalized Difference Vegetation Index (NDVI), the Enhanced Vegetation Index (EVI) [22, 39-40]. For instance, at global scale, [40] has demonstrated that the vegetation optical depth is statistically related with the aforementioned optical vegetation indexes in several land cover types. [39] computed relationships between optical depth, the vegetation water content (VWC) and vegetation indices derived from Landsat. Over the SMOSREX site, [26] computed a statistical relationship between optical depth and LAI using 2 years of measurements. Linear relationships between optical depth, LAI and the vegetation water content (VWC) where also obtained over several crop types [27] and considered in the L-MEB model for the SMOS level-2 processor level [23]. Therefore, based on these studies, we assumed here that the optical depth can be simply parameterized as a function of a vegetation index (NDVI, EVI, LAI, etc.). In this study we selected the NDVI, which is a very common optical vegetation index and which could be easily derived from the SMOSREX reflectance data set and the
MODIS products. Thus, we considered here that:

$$
\tau(p)=f(N D V I) \cong b_{1} \cdot N D V I
$$

where $b_{1}$ is a constant which accounts mainly for the effect of the vegetation structure. Using equations (10) and (8), soil moisture can be expressed as a function of the microwave reflectivity and the NDVI as:

$$
\log \left(w_{S}\right)=a_{1} \cdot \log (\Gamma(\theta, p))+b_{1} \cdot N D V I+c_{1}
$$

where $a_{l}$ and $c_{l}$ are regression coefficients.

The above equation was initially developed for one polarization and one incidence angle. However, it is valid for both Horizontal and Vertical polarizations and for all incidence angles. So, equations obtained at different polarizations and incidence angles can be summed. It is likely that the statistical regression will be more "efficient" if several angles and both polarizations are accounted for in the retrieval approach. For instance, considering eq. 11 at two different angles (denoted by indexes ' 1 ' and '2') and both $\mathrm{H}$ and $\mathrm{V}$ polarizations, and replacing the reflectivity by the ratio between the brightness and surface temperature $(\Gamma=1-T b / T c)$, the retrieved soil moisture can be expressed as:

$$
\begin{gathered}
\log \left(w_{s}\right)=a+b\left(\log \left(1-\frac{T b_{\theta 1, V}}{T c}\right)\right)+c\left(\log \left(1-\frac{T b_{\theta 2, V}}{T c}\right)\right)+ \\
d\left(\log \left(1-\frac{T b_{\theta 1, H}}{T c}\right)\right)+e\left(\log \left(1-\frac{T b_{\theta 2, H}}{T c}\right)\right)+f \cdot N D V I
\end{gathered}
$$

Where $a, b, c, d, e$ and $f$ are regression coefficients for the equation. Several preliminary tests (not shown in this study) were made and it was found that retrieval results could not be improved significantly if more than two angles were used. These tests also showed that best retrieval results were obtained for a single angle configuration (at the incidence angle of $40^{\circ}$ ) and for a bi-angle configuration combining observations made at the incidence angles of 20 and 40 degrees; these two configurations including bi-polarization observations. Only these two angles will be considered in the following

\section{DATA PROCESSING AND CALIBRATION/VALIDATION STRATEGY}

\section{A. SMOSREX in-situ data}

In order to calibrate the regression coefficients used in eq. 12, the SMOSREX data were processed in order filter and reorder the whole dataset. Only observations measured over the fallow were used here, as the focus of this study was on the correction of vegetation effects. Anomalous data or outliers were filtered out. Also, to avoid pondings effects, days which present rainfall greater than 0 and the day after were taken off 
from the data set. Another filter based on the polarization ratio index defined as $P R=(T b v-T b h) /(T b v+T b h)$, where $T b v$ and $T b h$ are the vertical and horizontal brightness temperature respectively, was applied to the data. This index allows the identification of soil frozen effects [29], and negative PR values indicate an inversion in magnitude of the $T b h$ over $T b v$, which is an anomalous pattern. Therefore, days with negative or very low PR (i.e. lower than the threshold equal to 0.02) as used by [26] were also filtered out.

Based on the filtered data, a statistical calibration process was carried out to obtain the best statistical correlations between soil moisture, brightness temperature (at 40 and 20 \& 40 degrees) and NDVI. These results were compared to the same statistical results obtained when NDVI was set equal to zero. In this way, the potential improvements obtained when NDVI is included in the retrieval process could be evaluated.

From the four years of available data (2004 to 2007), one year was used for the calibration of the semi-empirical regressions, and the other three years were used to evaluate its validation. Different combinations of years for the calibration/validation processes were used to better assess the robustness of the proposed retrieval approach. The retrieval results were evaluated using several statistical indexes: the coefficient of determination $\left(\mathrm{R}^{2}\right)$, as an estimate of the statistical fit $(p<0.05 *)$ and the Root Mean Square Error (RMSE) which was expressed as $\sqrt{\text { bias }^{2}+\sigma^{2}}$ where bias and $\sigma$ are the average and the standard deviation of the difference between the estimated and the observed values respectively.

\section{B. SMOS and MODIS remotely sensed data}

As an illustration of the potential application of the regression equations on actual spaceborne observations, the statistical retrieval approach was applied to the SMOS brightness temperatures available in the level 2 products over the eastern part of Australia. In this region of Australia, several international projects have been carried in the domain of soil moisture mapping over the last decade, as the International Soil Moisture Network (ISMN) [41] or SMOS calibration/validation field campaigns such as NAFE'06 field campaign [42].

First of all, an ensemble data matrix using SMOS DGG data, MODIS NDVI data and soil moisture from ERA-interim was created. The time matching process between all these data covered the time period from $16^{\text {st }}$ September to $31^{\text {th }}$ December 2010 with a 2 or 3 day time step depending on the SMOS overpass time. The statistical calibration was computed using the whole time period: no validation step as done for the SMOSREX data set was attempted, considering the rather short time period available for this Australian data set. As in the case of the SMOSREX data set, we also calibrated the regression equations using the NDVI index or not using it, in order to analyze to potential interest of using this index to account for the vegetation effects in the retrieval equations.

\section{RESULTS}

\section{A. Equation calibration from the SMOSREX data set}

Table 1 shows the results obtained in the calibration of the regression equations (12) from the SMOSREX in-situ data. As expected, better results in terms of $\mathrm{R}^{2}$ were obtained for the biangular configuration $\left(\theta=20^{\circ} \& \theta=40^{\circ}\right)$ than for the monoangular configuration (at $\theta=40^{\circ}$ ), the latter being a specific case of the bi-angular configuration. For both angular configurations (mono- and bi-angular), better results were obtained in terms of $\mathrm{R}^{2}$, when the NDVI index was included in the regression equation. The improvement in the results obtained using the NDVI index was larger for the monoangular configuration. This can be partially explained by the fact the NDVI brings information on the vegetation dynamics in the regression equation. In the soil moisture retrieval process, the vegetation effect can be better corrected from biangular and bi-polarization observations than from monoangular and bi-polarization observations [21]. From the obtained results, it seems that the information on the vegetation dynamics "brought" by the NDVI index is more "useful" in the mono-angular than in the bi-angular regression equations.

The calibration results are generally relatively similar whatever the years used for the calibration and validation processes. However, larger differences in terms of $\mathrm{R}^{2}$ were obtained for the mono-angular configuration without using NDVI (NDVI set equal to zero): the $\mathrm{R}^{2}$ varied from 0.861 using year 2004 for the calibration to 0.584, using year 2007 . More generally, slightly better results in the calibration were obtained for years 2004 and 2006, but no clear explanations could be found for this result. However, it should be noted that 2005 was a very dry year (precipitations over the site were even lower than those of 2003, the year of a big drought over Europe).

\section{B. Validation from the SMOSREX data}

The regression equations were calibrated using one year (see the above section) and then evaluated using the three other years. The RMSE between measured and retrieved soil moisture obtained using the calibrated regression equations are presented in Table 2. Conversely to the previous section, better results were generally obtained for the mono-angular configuration, which seems to be more robust when it is used in a "retrieval" mode.

As for the previous section, in most cases (except for the mono-angular configuration using year 2005 for calibration), the RMSE between observed and estimated soil moisture is lower when the NDVI index is used in the regression equations 
TABLE 1.- COEFFICIENTS OF DETERMINATION $\mathrm{R}^{2}\left(\mathrm{P}<0,05^{*}\right)$ OBTAINED IN THE CALIBRATION OF THE REGRESSION EQUATIONS ACCOUNTING FOR OR NOT ACCOUNTING FOR THE NDVI INDEX FOR EACH YEAR. FOR THE MONOANGULAR CONFIGURATION (AT 40 ${ }^{\circ}$ ) AND BI-ANGULAR (AT $20^{\circ}$ AND $\left.40^{\circ}\right)$.

\begin{tabular}{|c|c|c|c|c|c|c|c|c|}
\hline calibration year & $\mathbf{N}$ & $a$ & $b(\mathrm{TbV20})$ & $c(\mathrm{TbV40})$ & $d(\mathrm{TbH20})$ & $e(\mathrm{TbH} 40)$ & $f($ NDVI) & $\mathbf{R}^{2}$ \\
\hline 2004 & 516 & 1.559 & & 1.811 & & -0.763 & & 0.861 \\
\hline 2005 & 979 & 0.733 & & 1.719 & & -1.157 & & 0.654 \\
\hline 2006 & 800 & 1.337 & & 1.815 & & -0.956 & & 0.794 \\
\hline 2007 & 1243 & 1.035 & & 1.424 & & -0.607 & & 0.584 \\
\hline \multicolumn{9}{|c|}{ mono-angular configuration 40 - VH- accounting for NDVI } \\
\hline calibration year & $\mathbf{N}$ & $a$ & $b($ TbV20) & $c(\mathrm{TbV40})$ & $d($ TbH20) & $e(\mathbf{T b H 4 0 )}$ & $f($ NDVI) & $\mathbf{R}^{2}$ \\
\hline 2004 & 516 & 1.144 & & 1.814 & & -0.795 & 0.642 & 0.888 \\
\hline 2005 & 979 & 0.126 & & 2.028 & & -1.302 & 1.810 & 0.869 \\
\hline 2006 & 800 & 1.345 & & 2.176 & & -1.162 & 0.870 & 0.875 \\
\hline 2007 & 1243 & 0.474 & & 1.292 & & -0.392 & 1.162 & 0.788 \\
\hline \multicolumn{9}{|c|}{ Bi-angular configuration 20-40 - VH- NDVI = 0} \\
\hline calibration year & $\mathbf{N}$ & $a$ & $b(\mathrm{TbV20})$ & $c(\mathrm{TbV40})$ & $d($ TbH20) & $e(\mathbf{T b H 4 0})$ & $f(\mathrm{NDVI})$ & $\mathbf{R}^{2}$ \\
\hline 2004 & 516 & -0.730 & -6.456 & 3.356 & 5.850 & -2.826 & & 0.901 \\
\hline 2005 & 979 & 1.323 & 0.687 & 0.447 & 1.510 & -1.893 & & 0.798 \\
\hline 2006 & 800 & 0.423 & -4.641 & 2.144 & 4.941 & -1.888 & & 0.883 \\
\hline 2007 & 1243 & 0.572 & -0.829 & 0.925 & 2.348 & -1.844 & & 0.771 \\
\hline \multicolumn{9}{|c|}{ Bi-angular configuration 20-40 - VH- accounting for NDVI } \\
\hline calibration year & $\mathbf{N}$ & $a$ & $b($ TbV20) & $c($ TbV40) & $d($ TbH20 $)$ & $e(\mathrm{TbH} 40)$ & $f$ (NDVI) & $\mathbf{R}^{2}$ \\
\hline 2004 & 516 & -0.538 & -5.152 & 3.064 & 4.616 & -2.396 & 0.382 & 0.909 \\
\hline 2005 & 979 & 0.529 & 0.046 & 1.412 & 1.107 & -1.797 & 1.432 & 0.899 \\
\hline 2006 & 800 & 0.473 & -4.076 & 2.624 & 3.771 & -1.582 & 0.776 & 0.920 \\
\hline 2007 & 1243 & 0.319 & -1.271 & 1.359 & 1.869 & -1.235 & 0.806 & 0.811 \\
\hline
\end{tabular}

in comparison to the case where NDVI is set equal to zero. The minimum values of the RMSE $\left(0.051 \& 0.053 \mathrm{~m}^{3} / \mathrm{m}^{3}\right)$ were obtained for the mono-angular configuration and the calibration years 2005 and 2007 while the maximum values of the RMSE $\left(0.091 \& 0.095 \mathrm{~m}^{3} / \mathrm{m}^{3}\right)$ were obtained for the biangular configuration (NDVI $=0$ ) and the calibration years 2004 and 2005.

TABLE 2.- ROOT MEAN SQUARE ERROR (RMSE) VALUES BETWEEN MEASURED AND RETRIEVED SOIL MOISTURE FOR EACH VALIDATION YEAR FOR THE MONO AND BI ANGULAR CONFIGURATIONS (BOTH V \& H POLARIZATIONS) ACCOUNTING FOR NDVI OR SETTING NDVI EQUAL TO ZERO. THE RMSE VALUES WERE COMPUTED OVER THE VALIDATION PERIOD EXCLUDING THE YEAR USED FOR CALIBRATION (THIS LATTER IS GIVEN IN THE FIRST COLUMN). N REPRESENTS THE NUMBER OF OBSERVATION PHASES USED FOR THE RETRIEVALS.

\begin{tabular}{cc|cc|cc|ccccc|} 
& & \multicolumn{4}{|c|}{$\mathbf{4 0}^{\mathbf{0}} \mathbf{V H}$} & \multicolumn{4}{c|}{$\mathbf{2 0}$ and 40 } \\
& & \multicolumn{2}{|c}{ NDVI } & \multicolumn{2}{c|}{ NDVI=0 } & \multicolumn{2}{c|}{ NDVI } & \multicolumn{2}{c|}{ NDVI=0 } \\
\cline { 2 - 10 } & $\mathbf{N}$ & Bias & RMSE & Bias & RMSE & Bias & RMSE & Bias & RMSE \\
\hline $\mathbf{2 0 0 4}$ & 3022 & 0.0415 & 0.064 & 0.0445 & 0.075 & -0.0105 & 0.0642 & -0.032 & 0.0912 \\
$\mathbf{2 0 0 5}$ & 2559 & -0.0068 & 0.0677 & -0.0199 & 0.0518 & -0.018 & 0.0831 & -0.0405 & 0.0955 \\
$\mathbf{2 0 0 6}$ & 2738 & -0.0015 & 0.0577 & 0.0053 & 0.0638 & -0.0073 & 0.0617 & -0.0064 & 0.0652 \\
$\mathbf{2 0 0 7}$ & 2295 & -0.0009 & 0.0531 & 0.006 & 0.0571 & 0.0231 & 0.0538 & 0.0504 & 0.0782 \\
\hline
\end{tabular}


Illustrations of the retrieval results are given in Figures 3a-b which present the retrieved soil moisture for the year 2005 to 2007 using 2004 as the calibration year. The soil moisture estimations using the mono-angular approach are given in Figure 3a. We could note there are some periods where the observed soil moisture presents a positive bias in comparison to the estimated soil moisture (i.e. in spring or autumn seasons). Improved results using the NDVI index (RMSE = $0.064 \mathrm{~m}^{3} / \mathrm{m}^{3}$ versus $0.075 \mathrm{~m}^{3} / \mathrm{m}^{3}$ ) could generally be obtained during these periods. In comparison with the above results, a lower bias was obtained in the retrieved soil moisture using the bi-angular approach (figure $3 b$ ), especially when the NDVI index was used (bias $=-0.015 \mathrm{~m}^{3} / \mathrm{m}^{3}$ and $0.041 \mathrm{~m}^{3} / \mathrm{m}^{3}$, respectively, for the bi-angular and mono-angular regression equations using the NDVI index). Conversely, soil moisture tends to be over-estimated in winter ("wet" season). Also, outliers (i.e. large discrepancies between retrieved and measured soil moisture) were obtained for wet soil conditions mainly when NDVI was set equal to zero.

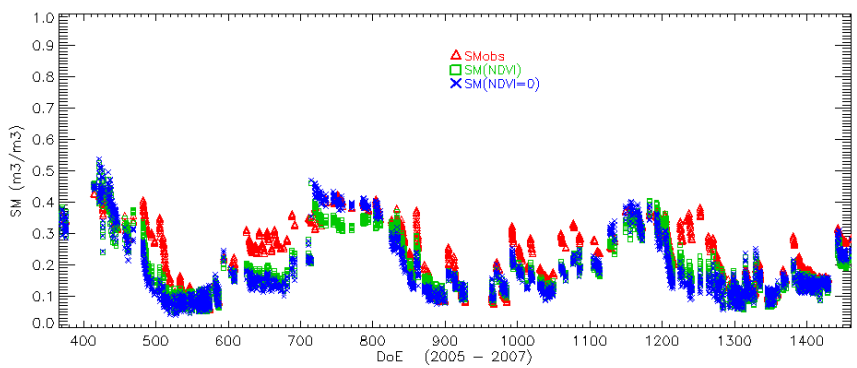

(a)

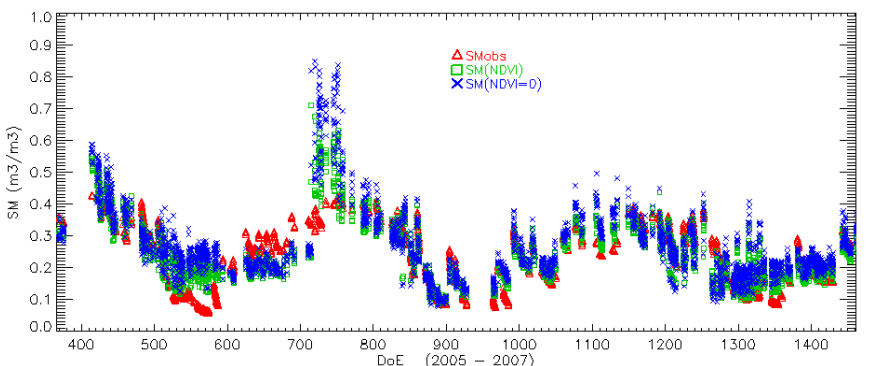

(b)

Fig. 3. Retrieved soil moisture estimations for the validation years 2005 to 2007 using the mono-angular configuration (a) and the bi-angular configuration at $20 \& 40$ degrees (b) over the SMOSREX site. Measurements of SM are represented by red triangle, the estimated soil moisture from the proposed regression equations are represented by green squares (when NDVI is accounted for in the equation) and blue crosses (when NDVI is set equal to zero).

\section{Calibration from SMOS and MODIS data: application to Australia}

The regression equations (12) were applied to the actual Level-2 SMOS brightness temperatures available over the eastern part of Australia. The coefficient of determination $\left(\mathrm{R}^{2}\right)$ resulting from the calibration of these equations is given in Figure 4. Low $\mathrm{R}^{2}$ values $(0-0.1)$ were obtained in a high proportion of the pixels when NDVI was set equal zero in the calibration process (figure 4a). However, results were strongly improved using using the NDVI index in the regression equation (figure $4 \mathrm{~b}$ ). In particular, the $\mathrm{R}^{2}$ coefficient of the calibration increased significantly in that case.

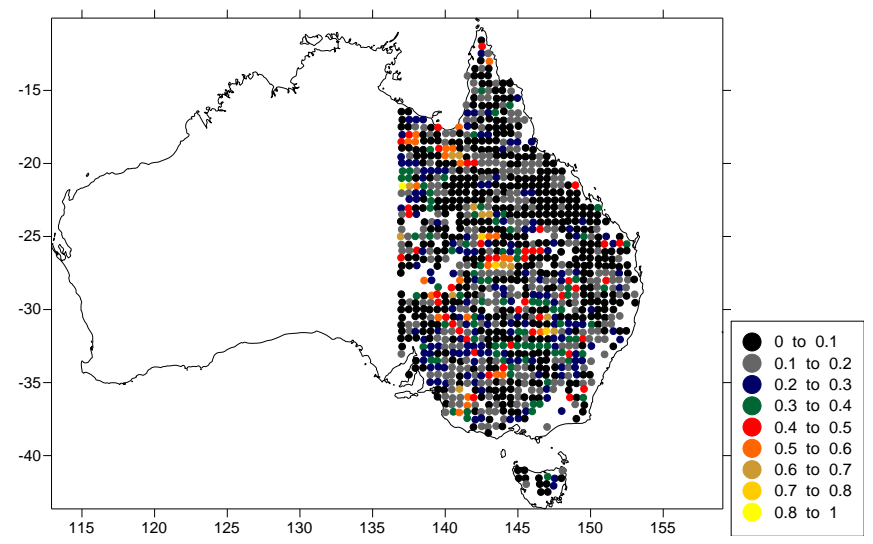

(a)

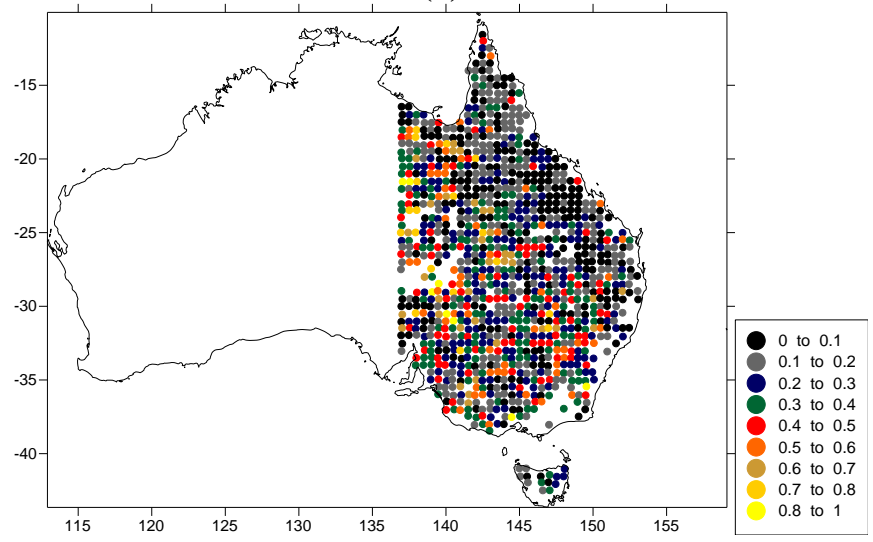

(b)

Fig. 4. Coefficient of determination $\left(\mathrm{R}^{2}, \mathrm{p}<0.05^{*}\right)$ of the regression equations computed from the SMOS and MODIS data for the eastern part of Australia during to the period covering September to December (a) setting $\mathrm{NDVI}=0$ and (b) accounting for the NDVI index in the regression equation. (Sept.-Dec., 2010)

Figure 5 shows the values of $\mathrm{R}^{2}$ larger than 0.6 obtained in a the pixels over the studies region (representing $\sim 10 \%$ of all the pixels)

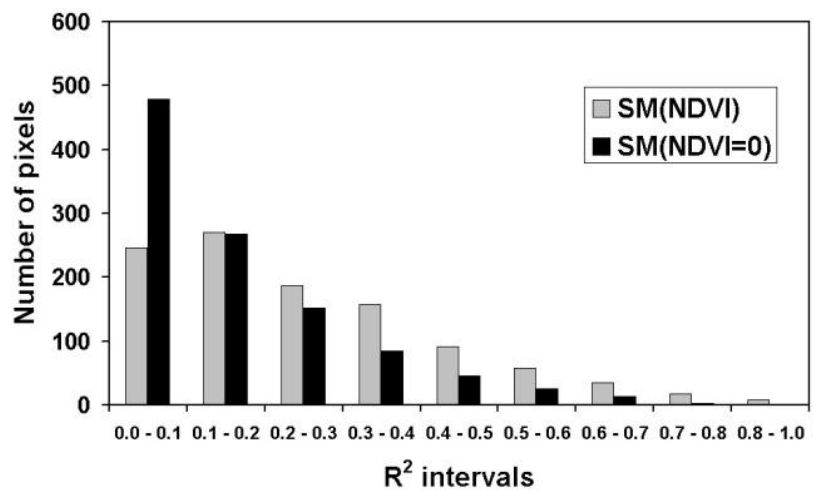

Fig. 5. Number of pixels for each coefficient of determination intervals estimated from the SMOS and MODIS observations over the eastern part of Autralia. 
Figure 6a presents the spatialized coefficient for the NDVI variable calibrated in the regression equation (ie the $\mathrm{f}$ coefficient in equation (12)). The map of this coefficient value was compared to the map of the GLC2000 global land cover (figure 6b). The regression coefficients of the NDVI are generally well related to the land cover type present in the eastern part of Australia. This result could be explained by the fact that this coefficient mainly depends on the vegetation structure which is largely determined by the land cover type.
As is shown in Figure 6a, the center part of Australia can be distinguished in blue colours (large and positive values of the regression coefficient for NDVI) and this area is characterized by bare soil, and semi-arid areas in the GLC2000 land cover type. An opposite case is obtained along the cost of the study area, where negative values of the regression coefficient for NDVI where obtained, while the land cover types correspond to more vegetated areas (forest and grassland and/or croplands with higher NDVI values).

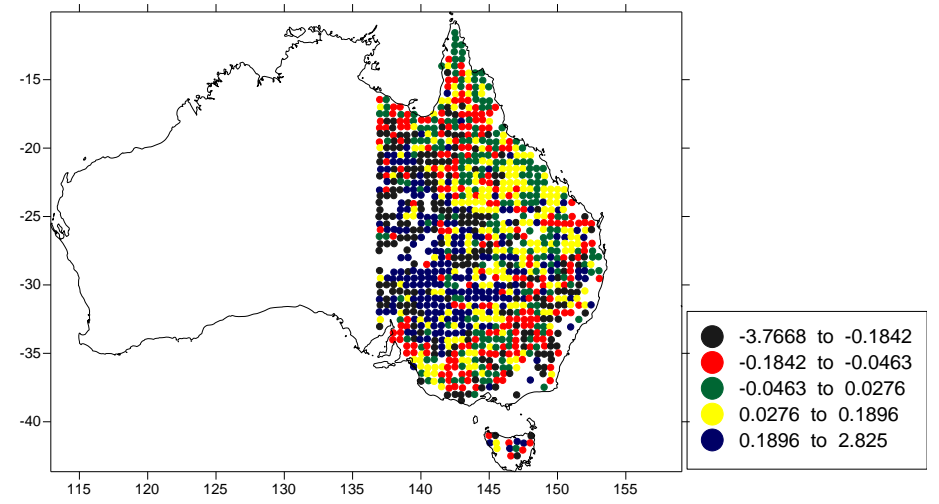

(a)

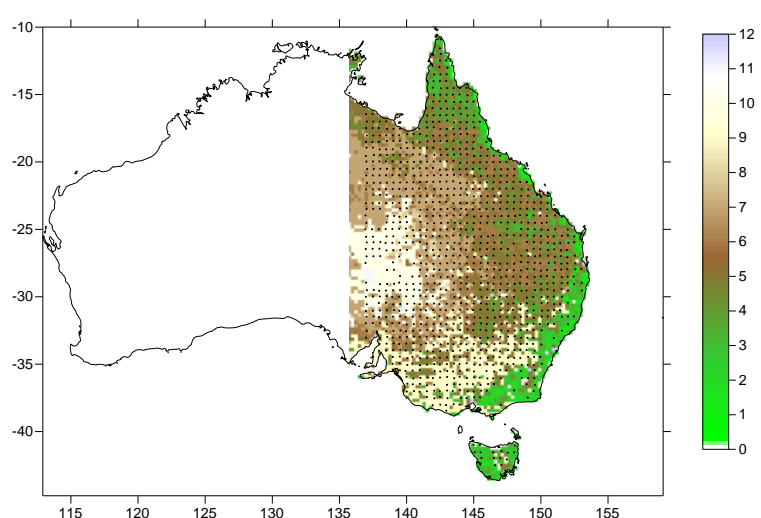

(b)

Fig. 6. (a) Regression coefficient of the NDVI variable for DGG points and (b) GLC2000 vegetation classification for the same region (black points represents the DGG points, the scale bar represents the vegetation cover fraction of each class from the highest vegetation fraction (1) to bare soil (12).

\section{SUMMARY AND CONCLUSIONS}

The algorithm presented in this paper attempted to improve the semi-empirical regression approach proposed by [24] to retrieve soil moisture from L-band passive microwaves observations. We evaluated whether the information on the vegetation dynamics provided by vegetation indexes measured in the optical domain (such as NDVI) could be useful to correct for the vegetation effects and improve the soil moisture retrievals. For both the calibration and the validation steps of this study, it was necessary to have an estimate of soil moisture which could be considered as a reference. However, obtaining such a "reference" soil moisture value is very difficult in most studies. Over SMOSREX, we used measurements from Tetaprobes. However these probes provide an estimate of the volumetric soil moisture over the $\sim 0-5 \mathrm{~cm}$ top soil layer which is significantly larger than the surface soil moisture "seen" by the L-band radiometer over the $\sim 0-3 \mathrm{~cm}$ top soil layer [43]. Also, these estimates are point measurements, located in an area which was not actually observed by LEWIS, while LEWIS provided an estimate of the soil moisture over large footprints that varied for each incidence angle.

Therefore, the soil moisture data used in the calibration and validation phases of this study are only indicative of the actual soil moisture conditions in the fallow field monitored by LEWIS and do not correspond to reference soil moisture values. This effect could explain some discrepancies between measured and retrieved soil moisture obtained in this study. For instance, in many cases, the point measurements of soil moisture by the in situ probes outside the LEWIS footprints did not represent correctly the effects of ponding due to strong rainfalls or hails. Despite this issue of representativeness of the in situ soil moisture values, the proposed regression algorithm showed good performances in soil moisture retrievals over the SMOSREX site.

At large spatial scale, a preliminary study was carried out to illustrate the potential application of the proposed regression algorithm to spaceborne observations. The algorithm calibration using SMOS and MODIS information over the eastern Australia has shown that improved performances of the regression model where obtained when the NDVI index is included in the regression equations. As over the SMOSREX site, the issue of the representativeness of the soil moisture derived from the ECMWF model simulations should also be taken into account in the evaluation of the obtained results. In particular, the ERA-Interim surface soil moisture also corresponds to a larger top soil layer than the one actually "seen" by SMOS. As for the NDVI coefficients, clear patterns could be identified in the spatial distribution of the regression coefficients for the NDVI variable and they could be related to the land cover types. However, the data time series was not long enough (approximately 4 months from September to December) to validate the algorithm.

In conclusion, the proposed semi-empirical approach combining microwave and optical observations provided promising results from the SMOSREX data set over the fallow field, even though, soil moisture retrievals have generally found to be very difficult over this very complex vegetation, due to the combined effects of the presence of litter, senescent vegetation, spatial heterogeneity in the vegetation type, structure and cover fraction [25-26, 44]. Analysis should be carried out to better evaluate the potential application of the proposed approach to long term spaceborne observations 
(which were only briefly illustrated over the eastern Australian regions in this study). Also, the NDVI index was used in this study as an estimate of the vegetation optical depth, although other indices such as the LAI, the Enhanced Vegetation Index (EVI) or the Normalized Difference Water Index (NDWI) are also interesting options to evaluate instead of NDVI. The use of these other vegetation indices will be evaluated in a future work at a large spatial scale and over a longer time period (more than one year at least to carry out both calibration and validation steps) from both SMOS and MODIS observations as made here over eastern Australia.

\section{ACKNOWLEDGMENTS}

The authors would like to thank the Spanish Ministerio de Ciencia y Tecnología (TERMASAT, project ESP2005-07724C05-04; EODIS, project AYA2008-0595-C04-01) in addition to the European Union (CEOP-AEGIS, project FP7-ENV2007-1 proposal No. 212921; WATCH, project 036946) for supporting the work presented in this paper. We also acknowledge the financial support from CNES (Centre National d'Etudes Spatiales, France, TOSCA program) and ESA (European Space Agency).

\section{REFERENCES}

[1] A. Beljaars, P., Viterbo, M. Miller, and A. Betts, "The anomalous rainfall over the United States during July 1993: sensitivity to land surface parameterization and soil moisture anomalies," Monthly Weather Rev., vol. 124, 362-383.,1996

[2] P.J. Wetzel, and J.T. Chang, "Evaporation from non-uniform surface: a first approach for short-term numerical weather prediction," Monthly Weather Rev., vo. 116, 600-621, 1988.

[3] M.F. Wilson, A. Hnderson-Sellers, R.., Dickinson, and P.J. Kennedy, "Sensititivty of the Biosphere-Atmosphere Transfer Scheme (BATS) to inclusion of variable soil characteristics," J. Climat Appl. Meteorl., 60, 341-362, 1987.

[4] M.J. Fennessy, and J. Shukla, "Impact of initial soil wetness on seasonal atmospheric prediction," J. Climate, 12, 3167-3180, 1999

[5] P.A. Diermeyer, "Using a global soil wetness dataset to improve seasonal climate simulation," J. Climate, 13, 2900-2922, 2000

[6] J. Leese, T. Jackson, A. Pitman, and P. Dirmeyer, "GEWEX/BAHC International workshop on soil moisture monitoring analysis and prediction for hydrometeorological and hydroclimatological applications," Bull. Amr. Meto. Soc., vol. 82, 1423-1430, 2001

[7] A.J. de Wit, and A.J. van Diepen, "Crop model data assimilation with the ensemble Kalman filter for improving regional crop yield forecasts," Agric. For. Meteorol., vol. 146, 38-56, 2007.

[8] M. Guerif, and C.I. Duke, "Adjustment procedures of a crop model to the site-specific characteristics of soil and crop using remote sensing data assimilation. Agric. Ecosyst. Environ., vol. 81(1), 57-69, 2000.

[9] E.A.B. Eltahir, "A soil moisture rainfall feedback mechanism 1 Theory and observations," Water Resour. Res. Vol. 34(4), 765-776, 1998.

[10] J. Noilhan, and J.-C. Calvet, "Mesoscale land-atmosphere models and data needs," in Proc. Passive Microw. Remote Sens. Land-Atmosphere Interactions," in Proc. Passive Microw. Remote Sens. Land-Atmosphere Interactions, ESA/NASA Int. Workshop, B. J. Choudhury, Y. Kerr, E. Njoku, and P. Pampaloni, Eds., St. Lary, France, pp. 17-54. 1995.

[11] E.F. Wood, .-S. Lin, P. A. Troch, M. Mancini, and T. J. Jackson, "Soil moisture estimation: Comparisons between hydrologic model estimates and remotely sensed estimates," in Proc. Passive Microw. Remote Sens. Land-Atmosphere Interactions, ESA/NASA Int. Workshop, B. J. Choudhury, Y. Kerr, E. Njoku, and P. Pampaloni, Eds., St. Lary, France, pp. 17-54. 1995.
[12] T. Carlson, "An overview of the "Triangle Method" for estimating surface evapotranspiration and soil moisture from satellite imagery," Sensors, 7, 1612-1629, 2007.

[13] K. Mallick, B.K. Bhattacharya, and NK. Patel, "Estimating volumetric surface moisture content for cropped soils using a soil wetness index based on surface temperature and NDVI," Agric. For. Meteor., vol. 149 (8), $1327-1342,2009$

[14] F. Ulaby, R. Moore, and A. Fung, "Microwave remote sensing-Active and passive," Norwood, MA: Artech House, 1986, vol. III.

[15] T. Schmugge, and T.J. Jackson, "Mapping soil moisture with microwave radiometers," Meteorl. Atmos. Phys., vol. 54, 213 - 233. 1994.

[16] T.J. Jackson, D.M. Le Vine, C.T. Swift, T. Schmugge, and F.R. Schiebe, "Large area mapping of soil moisture using the ESTAR passive microwave radiometer in Washita92," Rem. Sens. Environ, 53, 27 - 37, 1995.

[17] T. Pellarin, J. -P. Wigneron, J.C. Calvet, M. Berger, H. Douville, P. Ferrazzoli, Y. Kerr, E. López-Baeza, J. Paulliainen, L. Simmonds, and P. Waldteufel, "Two-Year Global Simulation of L-Band Brightness Temperatures Over Land," IEEE Trans. Geos. Rem. Sens. 2003, 41 (9), $2135-2139,2003$.

[18] J. -P. Wigneron, J.-C. Calvet, T. Pellarin, A. Van de Griend, M. Berger, and P. Ferrazzoli, "Retrieving near-surface soil moisture from microwave radiometric observations: current status and future plans," Remote Sensing, of Environment, 85, 489 - 506, 2003.

[19] Y. Kerr, P. Waldteufel, J. -P. Wigneron, J. -M. Martinuzzi, J. Font, and M. Berger, "Soil moisture retrieval from space: The soil moisture and ocean salinity (SMOS) mission," IEEE Transactions on Geoscience and Remote Sensing, 39(8), 1729-1735, 2001.

[20] D. Entekhabi, and co-authors, "The Soil Moisture Active Passive (SMAP) mission," Proceeding of the IEEE, 98(5), 704 - 716, 2009.

[21] J. -P. Wigneron, A. Chanzy, J. -C. Calvet and N. Bruguier, "A simple algorithm to retrieve soil moisture and vegetation biomass using passive microwave measurements over crop fields," Remote Sens. Environ. Vol. 51, 331-341, 1995.

[22] J. -P. Wigneron, Y. Kerr, P. Waldteufel, K. Saleh, M.-J. Escorihuela, P. Richaume, P. Ferrazzoli, P. de Rosnay, R. Gurney, J.-C. Calvet, J.P. Grant, M. Guglielmetti, B. Hornbuckle, C. Mätzler, T. Pellarin, and M. Schwank, "L-band Microwave Emission of the Biosphere (L-MEB) Model: Description and calibration against experimental data sets over crop fields," Remote Sensing of Environment, 107, 639 - 655, 2007.

[23] Y. Kerr, "SMOS level 2 Processor for Soil Moisture, Algorithm Theoretical Basis Document (ATBD)," 133 pp. 2010.

[24] J. -P. Wigneron. J. -C. Calvet, P. de Rosnay, Y. Kerr, P. Waldteufel, K. Saleh, M.J. Escorihuela and A. Kruszewski, "Soil moisture retrievals from biangular L-Band passive microwave observations," IEEE Geosc. Rem. Sens., 1(4), 277 - 281, 2004.

[25] K. Saleh, J. -P. Wigneorn, P. de Rosnay, J. -C. Calvet, and Y. Kerr, "Semi-empirical regressions at L-bad applied to surface soil moisture retrievals over grass," Rem Sens. Env., vol. 101, 415 - 426, 2006.

[26] K. Saleh, J. -P. Wigneron, P. de Rosnay, J. -C. Calvet, M.J. Escorihuela, Y. Kerr, and P. Waldteufel,'Impact of rain interception by vegetation and mulch on the L-band emission of natural grass," Rem Sens. Env, vol. 101, 127 - 139, 2006.

[27] J. -C. Calvet, J.-P. Wigneron, J. Walker, F. Karbou, A. Chanzy and C. Albergel, "Sensitivity of passive microwave observations to soil moisture and vegetation water content: from L-band to W-band," IEEETGRS, vol. 49(4), 1190-1199, 2011.

[28] A. Huete, and C. Justice, "MODIS vegetation index (MOD13) algorithm theoretical basis document," Ver. 3. 1999.

[29] P. de Rosnay and co-authors, "SMOSREX: A long term field campaign experiment for soil moisture and land surface processes remote sensing," Rem Sens. Env, 102, 377 - 389, 2006.

[30] F. Lemaître, J.C. Poussière, Y. Kerr, M. Dejus, R. Durbe, P. de Rosnay, and J. -C. Calvet., "Design and test of the ground based L-band radiometer for Estimating Water in Soils (LEWIS)," IEEE Transactions on Geoscience and Remote Sensing, vol. 42(8), 1666-1676, 2004.

[31] C. Albergel, and co-authors, "Monitoring of water and carbon fluxes using a land data assimilation system: a case study for southwestern France," Hydrol. Earth.Syst. Sci. 14, 1109 - 1124, 2010.

[32] A. Huete, K. Didan, T. Miura, E. P. Rodriguez, X. Gao, and L. G. Ferreira, "Overview of the radiometric and biophysical performance of 
the MODIS vegetation indices," Remote Sensing of Environment, vol. 83, 195-213, 2002.

[33] A. J. Simmons, S. Uppala, D. Dee, and S. Kobayashi, "Era interim. New ECMWF reanalysis product from 1989 onwards," ECMWF Newsl., 110, $25-35,2007$.

[34] T. Pellarin, and J.C. Calvet, "Influence of atmospheric properties on Lband microwave emission. Soil moisture retrieval by a future spaceborne earth observation mission," ESTEC contract number 1462/00/NL/DC, 2003.

[35] J. -P. Wigneron, M. Pardé, P. Waldteufel, A. Chanzy, Y. Kerr, A. Schmidl, and N. Skou, "Characterizing the dependence of vegetation parameters on crop type, view angle and polarization at L-band," IEEE Trans. Gesoci. Remote Sensing, vol. 42, 416 - 425, 2004.

[36] T.J. Jackson, D.M. Le Vine, A.Y. Hsu, A. Oldak, P.J. Tarks, C.T. Swift, J.D. Isham, and M. Haken, "Soil moisture mapping at regional scales using microwave radiometry: The Southern Great Plains Hydrology Experiment," IEEE Transc. Geosc. Remote Sensing, vol. 37, $2136-$ 2151, 1999.

[37] A. Guha, J.M. Jacobs, T. J. Jackson, M. H. Cosh, E. C. Hsu, and J. Judge, "Soil moisture mapping using ESTAR under dry conditions from the southern great plains experiment (SGP99)," IEEE Trans. Geosc. Remote Sens, 41(10), 2392 - 2397, 2003.

[38] A. Chanzy, T.J. Schmugge, J. -C. Calvet, Y. Kerr, P. van Oevelen, O. Grosjean, and J.R. Wang, "Airborne microwave radiometry on a semiarid are during HAPEX Sahel," Journal of Hydrology, vol. 189, 285 309, 1997.

[39] T. J. Jackson, Ch. Daoyi, M. Cosh, F. Li, M. Anderson, Ch. Walthall, P. Doriaswamy, and E. R. Hunt, "Vegetation water content mapping using Landsat data derived normalized difference water index for corn and soybeans," Rem Sens. Env. Vol. 92, 475-482, 2004.

[40] M. Jones, L. Jones, J. Kimball, and K. McDonald, "Satellite passive microwave remote sensing for monitoring global land surface phenology," Rem Sens. Env, vol. 115, 1102 - 1114, 2011.

[41] W. Dorigo, and co-authors, "The International Soil Moisture Network: a data hosting facility for global in situ soil moisture measurements," Hydrol. Earth Syst. Sci. Discuss, vol. 8, 1609-1663, 2011.

[42] O. Merlin, and co-authors, "The NAFE'06 data set: Towards Soil Moisture Retrieval at Intermediate Resolution," Advances in Water Resources, 31 (11), 1444-1455, 2008.

[43] M.J. Escorihuela, A. Chanzy, J. -P. Wigneron, and Y. Kerr, "Effective soil moisture sampling depth of L-band radiometry: A case study," Rem Sens. Env, Vol. 114(5-17), 995-1001, 2010.

[44] K. Saleh, J. -.P. Wigneron, P. Waldteufel, P. de Rosnay, M. Schwank, J. -C. Calvet, and Y. Kerr, "Estimates of surface soil moisture under grass covers using L-band radiometry" Rem Sens. Env, vol. 109, 42 - 53, 2007. 